\title{
FLUORESCENCE DECLINE RATIO: COMPARISON WITH QUANTUM YIELD RATIO FOR PLANT PHYSIOLOGICAL STATUS AND HERBICIDE TREATMENT RESPONSES
}

\author{
D.B. HORGAN and J.A. ZABKIEWICZ \\ Plant Protection Chemistry ${ }_{N Z}$, PO Box 6282, Rotorua, New Zealand \\ Corresponding author: david.horgan@ppcnz.co.nz
}

\begin{abstract}
Plant fluorescence is normally measured using the ratio Fv/Fm (quantum yield). An alternative measurement, fluorescence decline ratio $\left(\mathrm{R}_{\mathrm{fd}}\right)$, can be used instead of Fv/Fm. The usefulness of the $\mathrm{R}_{\mathrm{fd}}$ ratio in comparison to $\mathrm{Fv} / \mathrm{Fm}$ was tested with three plant species of differing leaf character. Diurnal trends were measured after treatment with two herbicides, diuron, a lipophilic photosynthesis inhibiting herbicide and dalapon, a less-lipophilic non-photosynthesis inhibiting herbicide. In wheat, both herbicides were tested with three non-ionic surfactants of differing hydrophilelipophile balance (HLB). The $\mathrm{R}_{\mathrm{fd}}$ ratio was a more sensitive numerical indicator of plant responses and provides an alternative approach to monitoring and measuring the effect of stress factors in plants.
\end{abstract}

Keywords: chlorophyll fluorescence, quantum yield, fluorescence decline ratio, herbicide effects.

\section{INTRODUCTION}

When a plant is under stress, one of the first symptoms that can be seen is a decrease in photosynthetic activity. Chlorophyll fluorescence (CF) is used to look at photosynthetic activity (Maxwell \& Johnson 2000) and can reflect the 'health' of a plant. CF measurement is rapid, non-invasive and can measure a number of parameters linked to the physiological status of the plant. The most common CF parameter used is the quantum yield $(\mathrm{Fv} / \mathrm{Fm})$, which is a measure of maximum photochemical efficiency of photosystem II. Another parameter that can show the physiological status of a plant under stress is the fluorescence decline ratio $\left(\mathrm{R}_{\mathrm{fd}}\right)$, which is obtained from the Kautsky curve (Lichtenhaler 1988). Compared to $\mathrm{Fv} / \mathrm{Fm}$ the $\mathrm{R}_{\mathrm{fd}}$ ratio is more sensitive to a variety of stress factors while Fv/Fm changes occur mainly under extreme conditions (Sayed 2003).

This paper investigated the applicability of $\mathrm{R}_{\mathrm{fd}}$ as an alternative to $\mathrm{Fv} / \mathrm{Fm}$ measurements for species responses, diurnal effects and the effect of herbicides with or without added surfactants.

\section{Plant material}

\section{METHODS}

The species used were fathen (Chenopodium album), wheat (Triticum aestivum) and Madagascar jasmine (Stephanotis floribunda). Each has a different cuticle thickness (fathen and wheat have a thin cuticle while Madagascar jasmine has a thick cuticle) and they differ in their response to xenobiotics (Forster et al. 2004). The fathen and wheat plants were grown from seed in individual pots (Bloom potting mix, Yates Ltd) and were raised under controlled environment conditions $\left(23^{\circ} \mathrm{C} / 15^{\circ} \mathrm{C}\right.$ and $20^{\circ} \mathrm{C} / 15^{\circ}$ day $/$ night temperature respectively, 14 hour photoperiod, $70 \% \mathrm{RH}$ and light intensity ca $500 \mu \mathrm{mol} / \mathrm{m}^{2} / \mathrm{s}$ ) and used 4 weeks after sowing. The jasmine plants were glasshouse grown and approximately 5 years old but transferred to controlled environment conditions for at least 2 weeks prior to being used. 


\section{Chemicals and treatments}

Technical dalapon acid (Zelam Ltd) and diuron (Dupont), all at 1\% a.i. in 50:50 acetone: water, were applied with a microsyringe to the adaxial surfaces of plant leaves $(14 \times 0.24 \mu \mathrm{l}$ droplets per leaf) at approximately $3 \mathrm{~h}$ after the start of the photoperiod. Leaf replication varied from 3-8 leaves per treatment (one fully expanded leaf per plant). These herbicides were also used with three alcohol ethoxylate adjuvants (triethylene glycol monododecyl ether, $\mathrm{C}_{12} \mathrm{EO}_{3}$; hexaethylene glycol monododecyl ether $\mathrm{C}_{12} \mathrm{EO}_{6}$; decaethylene glycol monododecyl ether $\mathrm{C}_{12} \mathrm{EO}_{10}$, all from Fluka) all at $0.2 \% \mathrm{v} / \mathrm{v}$.

\section{Instrumentation and analysis}

Chlorophyll fluorescence was measured using a Photon System Instruments Closed FluorCam 700MF. Using Fluorcam 5.0 version software and protocol \#4, fluorescence values for minimal fluorescence $(\mathrm{Fo})$, maximal fluorescence $(\mathrm{Fm})$, fluorescence peak (Fp) and steady state fluorescence (Ft) were obtained for the treated leaf areas. Fo was taken in the dark using dark adapted plant material prior to irradiating with a white light saturating pulse (of $1.6 \mathrm{~s}$ ) to obtain Fm. Forty seconds after the end of the saturating pulse, continuous actinic light (non-saturating red radiation) was switched on for $60 \mathrm{~s}$ producing a Kautsky response. Fp was measured at the initial phase of the Kautsky curve and Ft at a constant time (59 s) after Fp. Fv/Fm $[(\mathrm{Fm}-\mathrm{Fo}) / \mathrm{Fm}]$ and $\mathrm{R}_{\mathrm{fd}}[(\mathrm{Fp}-\mathrm{Ft}) / \mathrm{Fp}]$ parameters were derived from these measurements and these values used for comparison of effects. Readings were taken before the start of treatments ( $2 \mathrm{~h}$ after start of photoperiod), then at regular intervals $(4,8,12$ and $24 \mathrm{~h}$ after the initial reading). Plants were dark adapted at least 20 minutes prior to measurements being taken. Observations in visible light were also made over several days after treatment.

The statistical software package Statistix was used to analyse the wheat treatment results. Least significant difference (LSD) tests $(\mathrm{P}=0.05)$ were used to compare the variables time and treatment. These were both highly significant as was the interaction between treatment and time $\left(\mathrm{P}=0.0009\right.$ for $\mathrm{Fv} / \mathrm{Fm}$ analysis and $\mathrm{P}=0.0000$ for $\mathrm{R}_{\mathrm{fd}}$ analysis). The interaction between treatment and time has been used to illustrate the trends found.

\section{RESULTS AND DISCUSSION}

Untreated plants of the three species had slightly different initial Fv/Fm values (jasmine 0.766, wheat 0.837 and fathen 0.879 ), which stayed the same throughout the $24 \mathrm{~h}$ measuring period (data not shown). However, the $\mathrm{R}_{\mathrm{fd}}$ values (respectively 0.530 , 0.653 and 0.679 at time zero) did change during the day. This variation was most evident in fathen, where $\mathrm{R}_{\mathrm{fd}}$ values dropped to 0.584 (from 0.679 ) at midday before recovering. The other two species did not show a regular diurnal trend. The trends are virtually identical to those shown in Figure 1 after dalapon treatments. Diurnal variation was observed by Rohacek \& Bartak (1999) when monitoring spruce seedlings using $R_{\mathrm{fd}}$. A diurnal effect may be present with some species or conditions and needs to be considered when using the $\mathrm{R}_{\mathrm{fd}}$ parameter. This contrasts with the Fv/Fm ratio, which is insensitive to such effects.

Dalapon acid is a slightly lipophilic (log Kow 0.84 ) herbicide and has no direct effect on photosynthesis (Leasure 1963). There seemed to be no effect on the plants after treatment with dalapon (Fig. 1). There was little variation in Fv/Fm or $R_{f d}$ for any species other than due to diurnal variation. This may be due to lack of uptake of dalapon into the leaves, or, since dalapon does not have a direct effect on photosynthesis, it takes longer than $24 \mathrm{~h}$ for stress effects to show using CF. Visible damage to the leaves was observed after about 3 days with wheat and fathen but not with the jasmine, reflecting the different cuticle permeabilities. 


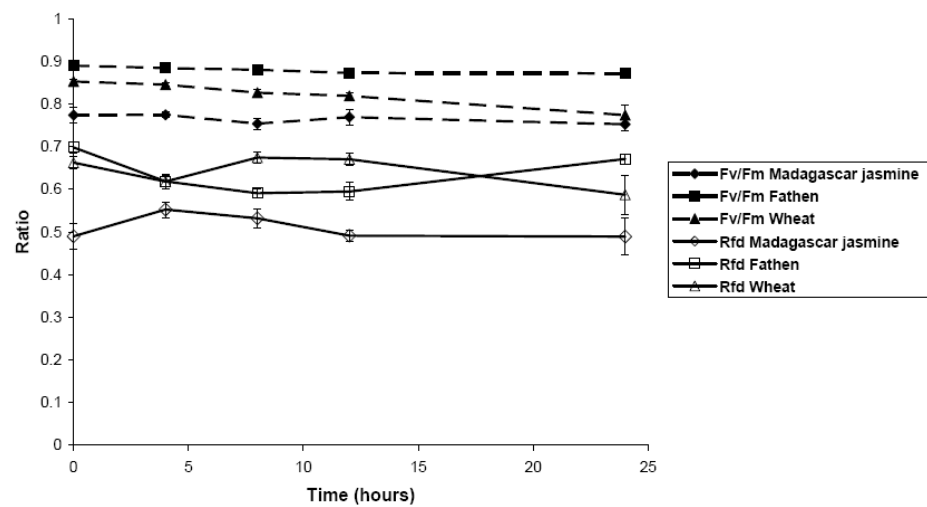

FIGURE 1: Mean Fv/Fm and $R_{\mathrm{fd}}$ values for fathen, wheat and Madagascar jasmine plants treated with dalapon over $24 \mathrm{~h}$. Error bars are \pm SEM.

Diuron is a lipophilic (log Kow 2.6) photosynthesis-inhibiting herbicide. The diuron did have an effect on $\mathrm{CF}$ for wheat and fathen plants (Fig. 2). There was a slight reduction in $\mathrm{Fv} / \mathrm{Fm}$ values over time but large changes in $\mathrm{R}_{\mathrm{fd}}$ values for both species. Diuron had little effect on jasmine, with $\mathrm{R}_{\mathrm{fd}}$ and $\mathrm{Fv} / \mathrm{Fm}$ values staying relatively constant. This may be due to the inability of diuron to penetrate the very thick and waxy jasmine cuticle. The lipophilic character of the diuron allows it to be taken up rapidly by some species but not by others, making the $\mathrm{CF}$ technique a rapid screening method for susceptibility or tolerance.

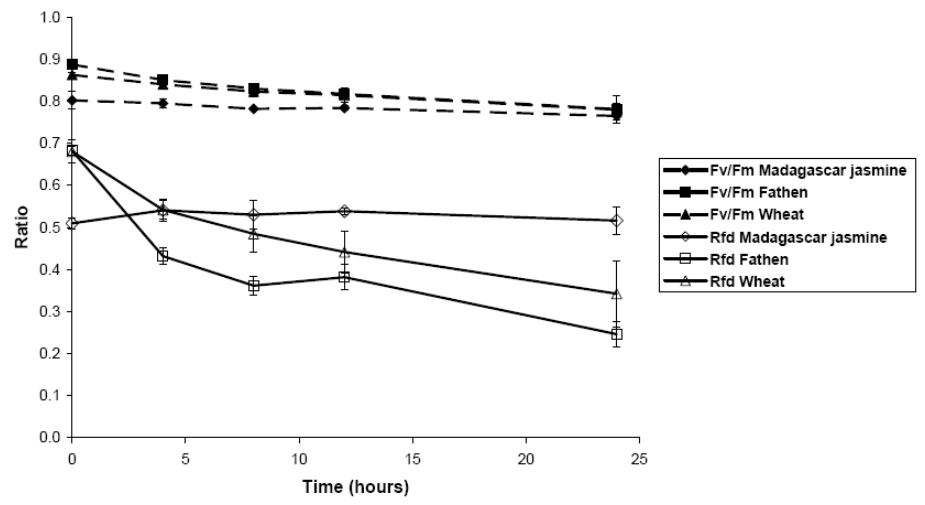

FIGURE 2: Mean Fv/Fm and $R_{\mathrm{fd}}$ values for fathen, wheat and Madagascar jasmine plants treated with diuron over $24 \mathrm{~h}$. Error bars are \pm SEM. 
The influence of adjuvants on herbicide effect was tested using wheat as the target species. The addition of alcohol ethoxylate surfactants to dalapon did not cause any changes in $\mathrm{CF}$ responses (data not shown), indicating these are inappropriate or that again a longer measurement interval is required for this type of herbicide.

In contrast, the addition of these surfactants to diuron produced a greater stress response in wheat. All the diuron treatments show a decline in both $\mathrm{Fv} / \mathrm{Fm}$ and $\mathrm{R}_{\mathrm{fd}} \mathrm{values}$, with $R_{\mathrm{fd}}$ showing a much greater decrease within $4 \mathrm{~h}$ (Tables 1,2). The most lipophilic surfactant, $\mathrm{C}_{12} \mathrm{EO}_{3}$, appeared to have the greatest influence. A statistical comparison of both $\mathrm{Fv} / \mathrm{Fm}$ (Table 1 ) and $\mathrm{R}_{\mathrm{fd}}$ (Table 2) values over the $24 \mathrm{~h}$ period showed that there were significant differences. These differences were most evident using the $R_{f d}$ values. There were significant differences in $\mathrm{R}_{\mathrm{fd}}$ values between the diuron treatment and the treatments with added surfactants. There was also a significant difference between surfactants at the 4 hour time period with $\mathrm{C}_{12} \mathrm{EO}_{3}$ being different to $\mathrm{C}_{12} \mathrm{EO}_{10}$ (Table 2). This shows that the $\mathrm{R}_{\mathrm{fd}}$ ratio was more responsive to the stress changes compared to $\mathrm{Fv} / \mathrm{Fm}$, showing there was variation over time as well as treatment.

TABLE 1: Fv/Fm values of wheat plants treated with diuron and various surfactants over $24 \mathrm{~h}$.

\begin{tabular}{lrrrr}
\hline Treatment & \multicolumn{5}{c}{ Time (hours) $^{1}$} \\
\cline { 2 - 6 } & 0 & 4 & 8 & 24 \\
\hline Control & $0.868 \mathrm{a}$ & $0.869 \mathrm{a}$ & $0.867 \mathrm{a}$ & $0.865 \mathrm{a}$ \\
Diuron & $0.864 \mathrm{a}$ & $0.840 \mathrm{ab}$ & $0.824 \mathrm{bc}$ & $0.780 \mathrm{de}$ \\
Diuron $+\mathrm{C}_{12} \mathrm{EO}_{3}$ & $0.870 \mathrm{a}$ & $0.806 \mathrm{~cd}$ & $0.785 \mathrm{de}$ & $0.795 \mathrm{cde}$ \\
Diuron $+\mathrm{C}_{12} \mathrm{EO}_{6}$ & $0.863 \mathrm{a}$ & $0.799 \mathrm{cde}$ & $0.780 \mathrm{de}$ & $0.791 \mathrm{de}$ \\
Diuron $+\mathrm{C}_{12} \mathrm{EO}_{10}$ & $0.872 \mathrm{a}$ & $0.826 \mathrm{bc}$ & $0.790 \mathrm{de}$ & $0.767 \mathrm{e}$ \\
\hline
\end{tabular}

${ }^{1}$ Treatments with no letter in common are significantly different $(\mathrm{P}=0.05)$.

\section{TABLE 2: $\quad \mathbf{R}_{\mathrm{fd}}$ values of wheat plants treated with diuron and various surfactants} over $24 h$.

\begin{tabular}{lcccc}
\hline Treatment & \multicolumn{5}{c}{ Time (hours) $^{1}$} \\
\cline { 2 - 5 } & 0 & 4 & 8 & 24 \\
\hline Control & $0.667 \mathrm{a}$ & $0.633 \mathrm{ab}$ & $0.635 \mathrm{ab}$ & $0.639 \mathrm{ab}$ \\
Diuron & $0.681 \mathrm{a}$ & $0.542 \mathrm{bc}$ & $0.485 \mathrm{c}$ & $0.343 \mathrm{de}$ \\
Diuron $+\mathrm{C}_{12} \mathrm{EO}_{3}$ & $0.654 \mathrm{a}$ & $0.252 \mathrm{efg}$ & $0.184 \mathrm{gh}$ & $0.127 \mathrm{~h}$ \\
Diuron $+\mathrm{C}_{12} \mathrm{EO}_{6}$ & $0.663 \mathrm{a}$ & $0.295 \mathrm{def}$ & $0.218 \mathrm{fgh}$ & $0.169 \mathrm{gh}$ \\
Diuron $+\mathrm{C}_{12} \mathrm{EO}_{10}$ & $0.663 \mathrm{a}$ & $0.379 \mathrm{~d}$ & $0.246 \mathrm{efg}$ & $0.120 \mathrm{~h}$ \\
\hline
\end{tabular}

${ }^{1}$ Treatments with no letter in common are significantly different $(\mathrm{P}=0.05)$.

Since individual measurements used to calculate Fv/Fm can be made much faster (a few seconds) than those for calculation of $\mathrm{R}_{\mathrm{fd}}$ (approximately $1 \mathrm{~min}$ ) it would be the preferred operational option. However, it may be less useful since $\mathrm{R}_{\mathrm{fd}}$ measurements can show differences within a few hours, compared to one or more days for the Fv/Fm measurements. 


\section{CONCLUSIONS}

The results obtained demonstrate that CF measurement can measure a number of different stress effects, including diurnal variation, different responses among species to herbicide treatment and the effect of different herbicide formulations.

The use of $\mathrm{R}_{\mathrm{fd}}$ instead of $\mathrm{Fv} / \mathrm{Fm}$ for chlorophyll fluorescence measurements provides an alternative approach to monitoring and measuring the effect of stress factors in plants. $\mathrm{R}_{\mathrm{fd}}$ is a more sensitive indicator for numerical comparisons, although due to diurnal effects, caution may be required when using this parameter.

\section{ACKNOWLEDGEMENTS}

This work was funded by the New Zealand Foundation for Research, Science and Technology (Contract No. C04X0202). Thanks are due to K.D. Steele for maintaining the controlled environment facility.

\section{REFERENCES}

Forster WA, Zabkiewicz J, Riederer M 2004. Mechanisms of cuticular uptake of xenobiotics into living plants: 1 . Influence of xenobiotic dose on the uptake of three model compounds applied in the absence and presence of surfactants into Chenopodium album, Hedera helix and Stephanotis floribunda leaves. Pest Management Science 60: 1105-1113.

Leasure JK 1963. The mode of action of dalapon. California Turfgrass Culture 13:19-22.

Lichtenthaler HK 1988. In vivo chlorophyll fluorescence as a tool for stress detection in plants. In: Lichtenthaler HK ed. Applications of Chlorophyll Fluorescence in Photosynthesis Research, Stress Physiology, Hydrobiology and Remote Sensing. Kluwer Academic, Dordrecht, the Netherlands. Pp. 129-142.

Maxwell K, Johnson GN 2000. Chlorophyll fluorescence - a practical guide. Journal of Experimental Botany 51: 659-668.

Rohacek K, Bartak M 1999. Technique of the modulated chlorophyll fluorescence: basic concepts, useful parameters, and some applications. Photosynthetica 37: 339-363.

Sayed OH 2003. Chlorophyll fluorescence as a tool in cereal crop research. Photosynthetica 41: 321-330. 